\title{
Treatment persistence behaviours in patients with type 2 diabetes (T2DM) after initiation of basal insulin: An exploratory analysis from a Spanish real-world sample
}

\author{
Miriam Rubio de Santos ${ }^{1 *}$, Irene Hadjiyianni ${ }^{2}$, Magaly Perez-Nieves ${ }^{3}$, Dachuang Cao ${ }^{3}$, Jasmina Ivanova ${ }^{4}$, Tatiana Dilla ${ }^{1}$ and \\ Juan José Gorgojo Martínez ${ }^{5}$
}

*Correspondence: rubio_miriam@lilly.com

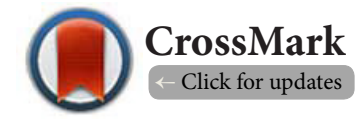

\begin{abstract}
'Lilly Spain, Avenida de la Industria, 30, 28108 Alcobendas, Madrid, Spain.
${ }^{2}$ Lilly Deutschland GmbH, Werner-Reimers-Straße 2, 61352 Bad Homburg vor der Höhe, Germany.

${ }^{3}$ Eli Lilly and Company, 893 S Delaware St, Indianapolis, IN 46225, USA.

${ }^{4}$ Analysis Group, Inc, 10 Rockefeller Plaza 15, New York, NY 10020, USA.

${ }^{5}$ Hospital Universitario Fundación Alcorcón, Calle Budapest 1, 28922 Alcorón, Madrid, Spain.
\end{abstract}

\begin{abstract}
Background: The real-world effectiveness of insulin therapy is influenced by poor treatment persistence. An international cross-sectional survey of people with type 2 diabetes mellitus (T2DM) was conducted to assess experiences before, during, and after basal insulin initiation, and to describe reasons for early nonpersistence with insulin therapy. A sub-analysis based on the Spanish cohort and notable between-group comparisons are presented.

Patients and methods: Responders to an online survey in seven countries were classified as continuers (no gap in insulin treatment $\geq 7$ days), interrupters (interrupted therapy for $\geq 7$ days within first 6 months, then restarted) and discontinuers (stopped insulin therapy within first 6 months and did not restart before the survey). Data from the Spanish subpopulation were analysed in combination and separately for the three persistence pattern groups.

Results: Of 942 global respondents, 150 (50 continuers, 50 interrupters, 50 discontinuers) were from Spain, with a mean age of 36 years and a mean of 6 years since first T2DM diagnosis. Reasons contributing to insulin continuation were improved glycaemic control (70\%) followed by improved physical feeling and the convenience of insulin relative to other diabetes treatments (both $46 \%$ ). Common reasons for interruption were weight gain (46\%), hypoglycaemia and the inconvenience of using insulin (both 40\%). Most common reasons for discontinuation were weight gain and pain from injections (both $40 \%$ ) followed by the dislike/ fear of needles (34\%).
\end{abstract}

Conclusion: The benefits of basal insulin therapy motivated continuers to persist with the treatment, whereas experienced or anticipated side effects and injection concerns contributed to interruption and discontinuation. Understanding factors affecting persistence patterns among Spanish patients with T2DM may help clinicians improve successful continuation of basal insulin therapy.

Keywords: Type 2 diabetes, persistence patterns, basal insulin, long-acting insulin, insulin initiation, Spain

\section{Introduction}

The prevalence of diabetes mellitus adjusted for age and sex in Spain is estimated to be $13.8 \%$, of which around half is undiagnosed [1].
The costs of diabetes to the Spanish healthcare system are high, reaching $8.2 \%$ of all expenditures in 2012 . Thirty-seven percent of this amount was spent on complications alone [2]. 
Rubio de Santos et al. Journal of Diabetes Research \& Clinical Metabolism 2019,

The recommended target levels of glycated haemoglobin ( $\mathrm{HbA} 1 \mathrm{c}$ ) from the Spanish treatment guidelines are $<6.5 \%$ for patients with type 2 diabetes mellitus (T2DM) $\leq 65$ years and without serious complications or comorbidities [3]. Only $32 \%$ of Spanish patients reach that target level. The less stringent level of $<7.5 \%$ is reached by $68 \%$ [4].

Good glycaemic control is crucial to prevent diabetic complications $[5,6]$. Basal insulin has a high efficacy in lowering blood glucose levels and should be considered an essential component of treatment strategy in patients not achieving an agreed $\mathrm{HbA} 1 \mathrm{c}$ target despite intensive therapy [7].

Treatment persistence is defined as the proportion of patients remaining on treatment for a specified period of time [8]. A high percentage of patients interrupt or discontinue insulin treatment shortly after initiation [9-11]. A large cohort study from the United States of America (USA) showed that the estimated probability of discontinuation was $61.5 \%$ in the first 90 days and $82.0 \%$ in the first year after insulin initiation [9]. A survey by Spain et al. [12] found that the barrier to maintaining injectable medication most commonly reported by T2DM patients from the USA was injection concerns (eg, aversion to needles, needle size, pain). The lack of perceived need was the most common reason for discontinuation of basal insulin.

There are only a few published studies that have investigated reasons behind insulin persistence in people with T2DM and have looked at interrupters and discontinuers separately $[13,14]$.

It is of great importance for clinicians treating people with T2DM to understand their concerns and challenges when initiating insulin treatment, as well as their motivations to continue. Additionally, knowing the reasons that are driving interruption, with or without re-start, or discontinuation of insulin in patients could be of great help for clinicians to enable them to take adequate measures before and during the insulin initiation process as well as throughout the therapy to meet patients' needs and support them to achieve the glycaemic targets.

We previously conducted an online survey with 942 individuals from seven different countries. As patients' reasons for persistence and initiation experience are likely to differ among countries $[\mathbf{1 4}, \mathbf{1 5}]$, they should be explored separately. The objectives of the present analysis were to assess patients experiences before, during, and after insulin initiation, and to investigate reasons behind patients' insulin persistence behaviour (continuation, interruption and discontinuation). Furthermore, we evaluated patients' feelings, challenges and concerns when initiating insulin. We evaluated and report data from the Spanish patient population only.

\section{Methods}

\section{Patients and study design}

Between July and September 2015, a cross-sectional online survey was conducted with a total of $942(\mathrm{~N})$ patients from
Spain, the United Kingdom (UK), the USA, France, Germany, Brazil and Japan $[13,16]$. Participants from Spain were identified from groups of volunteers who agreed to participate in surveys from Branded Research, Survey Sampling International, and Toluna. The panels included groups of volunteers with diabetes and general groups of volunteers who were later screened for T2DM. Panel members were invited to participate in the survey via email and were sent a unique link to the survey. No personal identifying information was collected as part of this study. Exemption from review was granted by the Western Institutional Review Board, Puyallup, WA, USA, due to the minimal risk to participants. Participants were compensated for their time according to market research panels' and the sponsor's compensation policies.

Adult (age $\geq 18$ years) insulin-naïve patients with T2DM who initiated a basal insulin analogue (ie, insulin glargine, insulin detemir or insulin degludec) within 3 to 24 months before the online survey were eligible for participation if they met the criteria for one of three persistence groups (continuers, interrupters and discontinuers). The present study focused only on patients initiating basal insulin analogue due to its wide use globally and to increase homogeneity across the sample.

Participants with no gap in basal insulin treatment of 7 days or more between treatment initiation and participation in the survey were allocated to the continuers group. Participants who interrupted basal insulin at least once for $\geq 7$ days within the first 6 months after initiation and had restarted by the time of the online survey were allocated to the interrupters group. The gap of $\geq 7$ days was considered long enough to define a period of interruption relevant to persistence behaviours, as well as to have clinical implications, while making it easy for patients to recall gaps in their treatment (ie, gaps of at least a full week). Participants who stopped basal insulin use within the first 6 months after treatment initiation and did not restart on any type of basal insulin before the survey were allocated to the discontinuers group. Individuals who interrupted for the first time or stopped insulin use later than 6 months following insulin initiation were not included. Pregnancy or breastfeeding at or after insulin initiation was an additional exclusion criterion. The global study had a target quota of 50 respondents per persistence group (continuers, interrupters, discontinuers) for each country (Spain, UK, USA, France, Germany, Brazil and Japan). The online survey was based on findings from semi-structured qualitative interviews of a total of 49 individuals with T2DM from the above-mentioned countries, including six participants from Spain. An interview guide with open-ended questions on their experiences during insulin initiation, use of insulin and reasons for their persistence patterns was developed.

The online survey consisted of two parts: The first part intended to establish patient eligibility, to categorise patients into one of the three persistence groups and to collect the participants' consent. Eligible individuals continued with the second part of the survey. This part covered topics including 
disease and treatment history, demographic and socioeconomic characteristics, basal insulin initiation experience, and experience while using basal insulin (ie, concerns before and after starting insulin, challenges during use, adverse events experienced), as well as reasons for different persistence patterns (continuation, interruption and discontinuation).

\section{Data analysis and statistics}

All statistical analyses were exploratory only. Data from the Spanish subpopulation were analysed in combination and separately for the three persistence pattern groups (continuers, interrupters, discontinuers). $t$-Tests (continuous variables) and Chi-squared tests (categorical variables) were used for pairwise comparisons between persistence pattern groups. Due to the moderate sample size and the nature of exploratory analysis, $p$-values were informative only and were used to assist in the identification of potential differences between continuers and interrupters and between continuers and discontinuers. Data of the overall Spanish population are presented, and only clini- cally impactful differences with $p$-values $<0.05$ between the persistence groups are described. Analyses were performed using SAS v.9.3 (Cary, NC, USA) software.

\section{Results \\ Patient characteristics}

The mean age (standard deviation [SD]) of the Spanish population ( $n=150$ ) was $36(10)$ years; only $11 \%$ of the population were 50 years or older (Table 1$)$. Continuers $(n=50)$ were on average older than interrupters $(n=50)$ and discontinuers $(n=50)$ (mean [SD] 41 [10], 34 [9] and 34 [9] years, respectively). Sixty percent of the participants were male, and continuers and interrupters were more likely to be male than discontinuers (62\% and $78 \%$ vs $40 \%$, respectively).

A higher percentage of interrupters (78\%) had prior use of antihyperglycaemic drugs (AHDs) before insulin compared with continuers (44\%) and discontinuers (42\%). Interrupters were more likely than continuers and discontinuers to have received oral AHDs (66\% vs $40 \%$ and $38 \%$, respectively) or

Table 1. Characteristics of the global and Spanish sample $(\mathrm{N}=150)$.

\begin{tabular}{|c|c|c|c|c|c|}
\hline & \multirow[t]{2}{*}{ Global } & \multicolumn{4}{|c|}{ Spanish population } \\
\hline & & Overall & Continuers & Interrupters & Discontinuers $^{*}$ \\
\hline Variable & $(n=942)$ & $(n=150)$ & $(n=50)$ & $(n=50)$ & $(n=50)$ \\
\hline \multicolumn{6}{|l|}{ Age, years } \\
\hline Mean (SD) & $41(14)$ & $36(10)$ & $41(10)$ & $34(9)^{*}$ & $34(9)^{*}$ \\
\hline$\geq 50$ yrs, $\%$ & 26 & 11 & 24 & 4 & 6 \\
\hline Male, \% & 67 & 60 & 62 & 78 & $40^{*}$ \\
\hline College degree, $\%$ & 52 & 43 & 34 & 42 & 54 \\
\hline \multicolumn{6}{|l|}{ Employment status, \% } \\
\hline Employed & 79 & 90 & 90 & 84 & 96 \\
\hline Not working $\dagger$ & 13 & 8 & 6 & 14 & 4 \\
\hline Retired & 8 & 2 & 4 & 2 & 0 \\
\hline $\begin{array}{l}\text { Years since first T2DM diagnosis, } \\
\text { mean (SD) }\end{array}$ & $7(7)$ & $6(7)$ & $6(7)$ & $7(7)$ & $6(7)$ \\
\hline \multicolumn{6}{|c|}{ Mode of delivery of basal insulin initiated, \% } \\
\hline Pen (prefilled/disposable) & 59 & 62 & 68 & 58 & 60 \\
\hline Pen (reusable) and cartridge & 29 & 25 & 28 & 24 & 22 \\
\hline Vial and syringe & 11 & 13 & 4 & 18 & 18 \\
\hline \multicolumn{6}{|c|}{ Months since initiation of basal insulin, \% } \\
\hline 3 to 6 & 29 & 28 & 28 & 22 & 34 \\
\hline 7 to 12 & 38 & 48 & 40 & 52 & 52 \\
\hline 13 to 24 & 33 & 24 & 32 & 26 & 14 \\
\hline $\begin{array}{l}\text { Prior use of any antihyperglycaemic } \\
\text { medication for T2DM, } \%^{*}\end{array}$ & 66 & 55 & 44 & $78^{\star}$ & 42 \\
\hline Oral antihyperglycaemic drugs & 58 & 48 & 40 & $66^{*}$ & 38 \\
\hline Injectables other than insulin & 24 & 19 & 8 & $36^{*}$ & 12 \\
\hline
\end{tabular}

Exploratory $\mathrm{p}$-value: ${ }^{\star} \mathrm{p}<0.05$ versus continuers.

${ }^{\star}$ Participants had to confirm that they had not restarted regular use (ie, daily injections) of any kind of basal insulin since they first stopped to be classified as a discontinuer.

†Not employed includes patients who ticked either 'not employed', 'disabled', 'student' or 'homemaker'. $\ddagger$ Respondents could tick several treatment options.

Abbreviations: $n$, number of participants; SD, standard deviation; T2DM, type 2 diabetes. 
Rubio de Santos et al. Journal of Diabetes Research \& Clinical Metabolism 2019,

non-insulin injectables ( $36 \%$ vs $8 \%$ and $12 \%$, respectively) prior to starting insulin.

No significant differences were found across persistence categories regarding educational attainment, or proportions employed/not working/retired. Disease duration was similar across all categories. No significant differences were found across categories for mode of delivery of basal insulin initiated, or time since initiation of basal insulin.

\section{Insulin initiation experience}

The most common motivation to start insulin was encouragement from a physician/healthcare provider (HCP) $(70 \%)$ followed by improved glycaemic control (48\%) and concern about developing other complications of diabetes (43\%). The main source of recommendation to start insulin was the primary care physician (62\%) followed by the endocrinologist (29\%). There were no differences between the persistence groups of continuers, interrupters and discontinuers regarding motivations to start or sources of recommendations. Overall, $37 \%$ of patients felt that their views were not at all or only slightly considered, while $33 \%$ had the feeling that their views were somewhat considered and 31\% felt that they were very much/ fully considered. The difference in the degree to which the respondents felt their views were considered was significant $(p<0.05)$ between continuers and discontinuers, with $26 \%$ of continuers and $58 \%$ of discontinuers feeling that their views were not at all/slightly considered and $46 \%$ of continuers and $6 \%$ of discontinuers feeling that their views were very much/ fully considered.
When participants were asked for their feelings regarding insulin, the majority agreed or strongly agreed with the following answer options: reassurance that insulin would help manage diabetes (79\%), the fear of developing other complications of diabetes $(77 \%)$ and the feeling that insulin indicated that diabetes was worsening (71\%). The belief that insulin was not necessary (44\%) and the sense of failure (39\%) were chosen by less than half of the participants. More discontinuers (58\%) than continuers $(32 \%)$ believed that insulin was not necessary $(p<0.05)$.

Overall, $55 \%$ of participants felt confident or very confident before their first self-injection of insulin, while $41 \%$ felt somewhat confident and only $4 \%$ not at all confident. The degree of self-confidence was different $(p<0.05)$ between continuers and discontinuers, with $68 \%$ of continuers and only $38 \%$ of discontinuers feeling confident or very confident.

Concerns before and after the first week of insulin initiation Participants were asked to what extent they agreed with the 14 potential concerns before insulin initiation (Table 2). The main concerns of the participants before starting insulin were the fear of self-injection (65\%), concern about potentially frequent hypoglycaemia (64\%), fear of making mistakes during self-injection (63\%), worry about potential weight gain (63\%) and concern that he/she would need to monitor blood glucose more often (63\%). Overall, no significant differences were found between persistence groups in mean number of concerns regarding insulin initiation (Figure 1a). However, more discontinuers than continuers expressed a fear of making mistakes during self-injection ( $78 \%$ vs $52 \%$ [ $p<0.05])$. Fewer

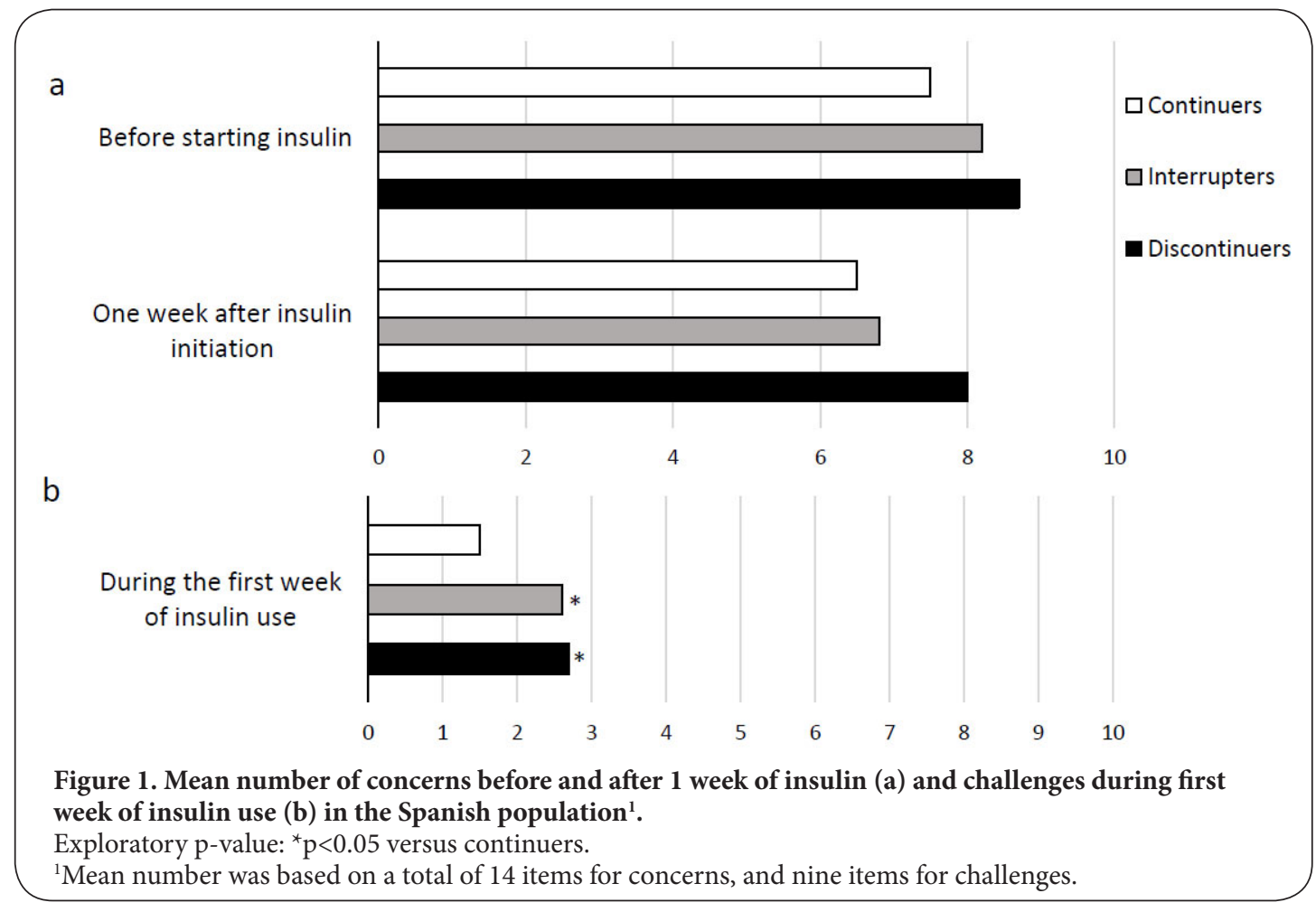


Table 2. Patient concerns before starting and after the first week of insulin in the Spanish sample.

\begin{tabular}{|c|c|c|c|c|c|c|c|c|}
\hline \multirow[t]{2}{*}{ Concerns $^{1}$} & \multicolumn{4}{|c|}{ Before starting insulin } & \multicolumn{4}{|c|}{ After first week of insulin } \\
\hline & $\begin{array}{l}\text { Continuers } \\
(\mathrm{N}=50)\end{array}$ & $\begin{array}{l}\text { Interrupters } \\
(\mathrm{N}=50)\end{array}$ & $\begin{array}{l}\text { Discontinuers } \\
(\mathrm{N}=50)\end{array}$ & $\begin{array}{l}\text { TOTAL } \\
(\mathrm{N}=150)\end{array}$ & $\begin{array}{l}\text { Continuers } \\
(\mathrm{N}=50)\end{array}$ & $\begin{array}{l}\text { Interrupters } \\
(\mathrm{N}=50)\end{array}$ & $\begin{array}{l}\text { Discontinuers } \\
(\mathrm{N}=50)\end{array}$ & $\begin{array}{l}\text { TOTAL } \\
(\mathrm{N}=150)\end{array}$ \\
\hline $\begin{array}{l}\text { Worry that insulin would } \\
\text { not/will not provide } \\
\text { glycaemic control }\end{array}$ & $52 \%$ & $58 \%$ & $66 \%$ & $59 \%$ & $50 \%$ & $56 \%$ & $62 \%$ & $56 \%$ \\
\hline $\begin{array}{l}\text { Fear/discomfort of } \\
\text { self-injection }\end{array}$ & $60 \%$ & $62 \%$ & $74 \%$ & $65 \%$ & $50 \%$ & $32 \%$ & $72 \% *$ & $51 \%$ \\
\hline $\begin{array}{l}\text { Fear of making mistakes } \\
\text { during self-injection }\end{array}$ & $52 \%$ & $60 \%$ & $78 \% *$ & $63 \%$ & $56 \%$ & $58 \%$ & $66 \%$ & $60 \%$ \\
\hline $\begin{array}{l}\text { Worry about/bothered } \\
\text { by scarring or bruising } \\
\text { resulting from injections }\end{array}$ & $46 \%$ & $56 \%$ & $54 \%$ & $52 \%$ & $46 \%$ & $48 \%$ & $58 \%$ & $51 \%$ \\
\hline $\begin{array}{l}\text { Worry about/burdened by } \\
\text { proper insulin storage }\end{array}$ & $58 \%$ & $50 \%$ & $72 \%$ & $60 \%$ & $42 \%$ & $40 \%$ & $54 \%$ & $45 \%$ \\
\hline $\begin{array}{l}\text { Concern about/burdened } \\
\text { by carrying insulin around }\end{array}$ & $58 \%$ & $60 \%$ & $64 \%$ & $61 \%$ & $46 \%$ & $42 \%$ & $54 \%$ & $47 \%$ \\
\hline $\begin{array}{l}\text { Worry that regular insulin } \\
\text { use would interfere/feeling } \\
\text { that it does interfere with } \\
\text { daily activities }\end{array}$ & $54 \%$ & $58 \%$ & $54 \%$ & $55 \%$ & $42 \%$ & $48 \%$ & $44 \%$ & $45 \%$ \\
\hline $\begin{array}{l}\text { Worry about/burdened } \\
\text { by need to visit physician/ } \\
\text { nurse more often }\end{array}$ & $42 \%$ & $64 \%^{*}$ & $62 \%^{*}$ & $56 \%$ & $34 \%$ & $56 \%{ }^{*}$ & $52 \%$ & $47 \%$ \\
\hline $\begin{array}{l}\text { Concern about/burdened } \\
\text { by need to monitor blood } \\
\text { glucose more often }\end{array}$ & $64 \%$ & $58 \%$ & $66 \%$ & $63 \%$ & $40 \%$ & $42 \%$ & $62 \%^{*}$ & $48 \%$ \\
\hline $\begin{array}{l}\text { Concern about/bothered } \\
\text { by potentially frequent } \\
\text { hypoglycaemia }\end{array}$ & $66 \%$ & $64 \%$ & $62 \%$ & $64 \%$ & $58 \%$ & $58 \%$ & $68 \%$ & $61 \%$ \\
\hline $\begin{array}{l}\text { Concern about becoming } \\
\text { insulin dependent }\end{array}$ & $58 \%$ & $62 \%$ & $50 \%$ & $57 \%$ & $54 \%$ & $54 \%$ & $48 \%$ & $52 \%$ \\
\hline $\begin{array}{l}\text { Concern about/burdened } \\
\text { by ability to pay for insulin } \\
\text { therapy }\end{array}$ & $34 \%$ & $50 \%$ & $58 \% *$ & $47 \%$ & $40 \%$ & $32 \%$ & $44 \%$ & $39 \%$ \\
\hline $\begin{array}{l}\text { Worry about potential/ } \\
\text { bothered by weight gain }\end{array}$ & $60 \%$ & $64 \%$ & $64 \%$ & $63 \%$ & $42 \%$ & $60 \%$ & $60 \%$ & $54 \%$ \\
\hline $\begin{array}{l}\text { Worry about/discomfort } \\
\text { injecting insulin in front of } \\
\text { other people }\end{array}$ & $48 \%$ & $58 \%$ & $48 \%$ & $51 \%$ & $50 \%$ & $50 \%$ & $54 \%$ & $51 \%$ \\
\hline
\end{tabular}

Exploratory p-value: ${ }^{\star} \mathrm{p}<0.05$ versus continuers. Data are percentage of patients in the persistence groups who agree/strongly agree.

${ }^{1}$ Wording differs depending on whether the concern was assessed before starting insulin/after first week of insulin (respectively).

Abbreviations: N, number of participants.

continuers than discontinuers or interrupters expressed concerns that they would need to visit the physician/nurse more often ( $42 \%$ for continuers vs $62 \%$ for discontinuers [ $p<0.05$ ] and $64 \%$ for interrupters $[p<0.05])$. More discontinuers than continuers were concerned about their ability to pay for insulin therapy $(58 \%$ vs $34 \%[p<0.05])$. After the first week of insulin use, the percentage of participants having concerns either dropped or stayed the same for all 14 items, with the most pronounced decreases seen in concerns about proper insulin storage (from $60 \%$ at initiation to $45 \%$ at 1 week after initiation), monitoring blood glucose more often (from 63\% to $48 \%$ ), and self-injection (from $65 \%$ at initiation to $51 \%$ at
1 week after initiation). Similar to before initiation, no significant differences were found between persistence groups in mean number of concerns at 1 week after initiation (Figure 1a). Across persistence groups, more discontinuers than continuers were concerned about discomfort regarding self-injection ( $72 \%$ vs $50 \%, p<0.05)$ or by the need to monitor blood glucose more often $(62 \%$ vs $40 \%, p<0.05)$. More interrupters than continuers were concerned about the need to visit the physician/nurse more often $(56 \%$ vs $34 \%, p<0.05)$.

\section{Insulin use experience}

Participants were asked about the difficulty of nine pre-specified 
challenges during the first week of insulin use. Most patients experienced injecting insulin (34\%) and dealing with the emotions about needing insulin (30\%) and titration (28\%) as difficult or very difficult, followed by more frequent blood glucose monitoring (25\%), worry about reactions to insulin use from friends/family (25\%), feeling confident about treating hypoglycaemia (22\%), remembering to inject insulin regularly $(21 \%)$, making time during the day to inject insulin (21\%) and proper insulin storage (18\%). More discontinuers than continuers reported that injecting insulin ( $54 \%$ vs $22 \%$ $[p<0.05])$ and feeling confident about treating hypoglycaemia ( $28 \%$ vs $10 \%[p<0.05])$ was difficult or very difficult. More interrupters than continuers stated that making time during the day to inject insulin ( $24 \%$ vs $12 \%$ [ $p<0.05])$, feeling confident about treating hypoglycaemia ( $28 \%$ vs $10 \%[p<0.05]$ ) and the worry about reactions from friends/family (34\% vs $14 \%$ $[p<0.05])$ was difficult or very difficult. The overall number of challenges was 2.3 , with continuers having fewer difficulties (1.5) compared with discontinuers $(2.7[p<0.05])$ or interrupters $(2.6[p<0.05])$ (Figure $1 \mathbf{b})$.

Patients were asked whether they had experienced uncontrolled high blood glucose, symptoms of hypoglycaemia, weight gain or injection site reactions while they were on insulin therapy. Forty-three percent reported having experienced weight gain, followed by symptoms of hypoglycaemia (35\%), uncontrolled high blood glucose (26\%) and injection site reactions (16\%). More discontinuers than continuers experienced uncontrolled high blood glucose ( $38 \%$ vs $16 \%$ $[p<0.05])$, while a higher proportion of interrupters experienced symptoms of hypoglycaemia compared with continuers ( $48 \%$ vs $26 \%$ [p<0.05]). These results may be biased due to the different timeframes for which continuers, interrupters and discontinuers were exposed to insulin treatment.

\section{Factors in persistence patterns}

Reasons for continuation

When continuers $(n=50)$ were asked for their motivation to take insulin, the majority (70\%) chose improved glycaemic control followed by an improved physical feeling and the convenience of insulin relative to other diabetes treatments (both 46\%) (Table 3). These reasons were followed by improved emotional well-being (38\%), instruction by physician/HCP to continue (32\%) and the belief that insulin is best for reducing the risk of complications of diabetes (26\%). Overall, $68 \%$ chose more than one reason for continuing.

\section{Reasons for interrupting and restarting}

The most common reasons for interruption $(n=50)$ were weight gain (46\%), hypoglycaemia and the inconvenience of using insulin (both 40\%) (Table 4). Interestingly, $65 \%$ of those that interrupted because of weight gain stated that they actually experienced it, and only $55 \%$ of participants interrupting because of hypoglycaemia actually experienced it. A further reason stated by more than $25 \%$ of participants was the fear of potential side effects of insulin use (26\%). Sixty-six percent of interrupters had stopped and re-started insulin more than once since initiation, and $66 \%$ stated that the duration of the interruption was 1 week. The most important factor contributing to restarting insulin was persuasion by a physician/HCP (72\%).

The most common methods of managing blood glucose during interruption were diet (78\%), exercise (66\%) and other AHDs, mostly oral AHDs (58\%) (Table 5). Only $16 \%$ used noninsulin injectables. Forty-eight percent of interrupters stated that their blood glucose levels were the same as before the interruption, $46 \%$ stated that their levels were higher than before the interruption and $6 \%$ stated that they were lower. All patients stated that they monitored their blood glucose levels during the interruption.

\section{Reasons for discontinuing and potential reasons for restarting}

Among 50 discontinuers in Spain, the most common factors contributing to stopping insulin therapy were weight gain and

Table 3. Motivations for continuation of basal insulin in the global and Spanish samples.

\begin{tabular}{|c|c|c|}
\hline Variable & $\begin{array}{l}\text { Global }^{1}(\mathrm{~N}=942) \\
\text { Continuers: } \mathrm{n}=357\end{array}$ & $\begin{array}{l}\operatorname{Spain}^{2}(N=150) \\
\text { Continuers: } n=50\end{array}$ \\
\hline \multicolumn{3}{|l|}{ Motivation for continuation of basal insulin, $\%$} \\
\hline Improved glycaemic control & $71 \%$ & $70 \%$ \\
\hline Improved physical feeling & $48 \%$ & $46 \%$ \\
\hline Convenience of insulin relative to other diabetes treatment & $30 \%$ & $46 \%$ \\
\hline Improved emotional well-being & $33 \%$ & $38 \%$ \\
\hline Belief that insulin is best for reducing risk of complications of diabetes & $45 \%$ & $26 \%$ \\
\hline Instruction by physician/HCP to continue & $35 \%$ & $32 \%$ \\
\hline Other & $1 \%$ & $2 \%$ \\
\hline At least one of the above & $100 \%$ & $100 \%$ \\
\hline At least two of the above & $71 \%$ & $68 \%$ \\
\hline
\end{tabular}

${ }^{1}$ Overall results were weighted to give equal representation to each of the seven countries in our data. Due to rounding, some counts may not sum to equal one another and some percentages may not appear correct.

${ }^{2}$ Results specific to Spain were not weighted.

Abbreviations: HCP, healthcare provider. 
Table 4. Factors involved in interruption/discontinuation of basal insulin in the global and Spanish samples.

\begin{tabular}{|c|c|c|c|c|}
\hline \multirow[t]{2}{*}{ Variable } & \multicolumn{2}{|c|}{ Interruption } & \multicolumn{2}{|c|}{ Discontinuation } \\
\hline & $\begin{array}{l}\text { Global }^{1} \\
(\mathrm{~N}=942) \\
\text { Interrupters: } \\
\mathrm{n}=330\end{array}$ & $\begin{array}{l}\text { Spain }^{2} \\
(\mathrm{~N}=150) \\
\text { Interrupters: } \\
\mathbf{n}=\mathbf{5 0}\end{array}$ & $\begin{array}{l}\text { Global }^{1} \\
(\mathrm{~N}=942) \\
\text { Discontinuers: } \\
\mathrm{n}=255\end{array}$ & $\begin{array}{l}\text { Spain }^{2} \\
(\mathrm{~N}=150) \\
\text { Discontinuers: } \\
\mathbf{n}=\mathbf{5 0}\end{array}$ \\
\hline \multicolumn{5}{|l|}{ Factors contributing to interruption/discontinuation, \% } \\
\hline Hypoglycaemia & $33 \%$ & $40 \%$ & $31 \%$ & $20 \%$ \\
\hline Experienced hypoglycaemia* & $48 \%$ & $55 \%$ & $48 \%$ & $30 \%$ \\
\hline Fear of potential side effects of insulin use & $25 \%$ & $26 \%$ & $19 \%$ & $26 \%$ \\
\hline Pain from injections & $28 \%$ & $24 \%$ & $27 \%$ & $40 \%$ \\
\hline Dislike/fear of needles & $18 \%$ & $12 \%$ & $19 \%$ & $34 \%$ \\
\hline Instruction by physician/HCP to stop & $20 \%$ & $10 \%$ & $26 \%$ & $28 \%$ \\
\hline Assessing whether/Sense that diabetes could be managed without insulin ${ }^{3}$ & $23 \%$ & $20 \%$ & $27 \%$ & $14 \%$ \\
\hline Insufficient glycaemic control with insulin & $11 \%$ & $10 \%$ & $10 \%$ & $20 \%$ \\
\hline At home & $6 \%$ & $10 \%$ & $7 \%$ & $4 \%$ \\
\hline Cost of insulin therapy & $10 \%$ & $10 \%$ & $17 \%$ & $30 \%$ \\
\hline Perception of insulin by others & $3 \%$ & $0 \%$ & $3 \%$ & $0 \%$ \\
\hline Other & $2 \%$ & $0 \%$ & $2 \%$ & $0 \%$ \\
\hline At least one of the above & $100 \%$ & $100 \%$ & $100 \%$ & $100 \%$ \\
\hline At least two of the above & $69 \%$ & $68 \%$ & $62 \%$ & $74 \%$ \\
\hline \multicolumn{5}{|l|}{ Factors that could contribute to restarting basal insulin, \% } \\
\hline Persuasion by physician/HCP to restart & $71 \%$ & $72 \%$ & $69 \%$ & $78 \%$ \\
\hline Persuasion by friends/family to restart & $39 \%$ & $38 \%$ & $33 \%$ & $26 \%$ \\
\hline Insufficient glycaemic control without insulin & $27 \%$ & $20 \%$ & $36 \%$ & $30 \%$ \\
\hline Resolution of the issue that led to the interruption & $11 \%$ & $8 \%$ & $\mathrm{~N} / \mathrm{A}$ & $\mathrm{N} / \mathrm{A}$ \\
\hline Other & $1 \%$ & $0 \%$ & $1 \%$ & $0 \%$ \\
\hline
\end{tabular}

*The $\%$ s are based on the number of patients who report hypoglycaemia/weight gain as reasons for interruption and discontinuation.

${ }^{1}$ Overall results were weighted to give equal representation to each of the seven countries in our data. Due to rounding, some counts may not sum to equal one another and some percentages may not appear correct.

${ }^{2}$ Results specific to Spain were not weighted.

${ }^{3}$ Different wording depending on whether the factor was assessed in interrupters/discontinuers (respectively).

Abbreviations: HCP, healthcare provider; N/A, not applicable.

pain from injections (both 40\%) (Table 4). Sixty-five percent of individuals discontinuing because of weight gain reported that they had actually experienced weight gain, and only $30 \%$ of participants discontinuing because of hypoglycaemia ( $20 \%$ of discontinuers) stated that they experienced hypoglycaemia. Additional reasons for discontinuation of insulin reported by more than $25 \%$ were dislike/fear of needles (34\%), cost of insulin therapy (30\%), instruction by physician/HCP to stop $(28 \%)$ and the fear of potential side effects of insulin use (26\%). All of the reasons for discontinuation to choose from - except for others' perception of insulin use (0\%) - were reported by more than $10 \%$ of discontinuers.

Similar to interrupters, participants managed their blood glucose levels after discontinuation mostly by diet ( $82 \%)$, exercise (72\%) and oral AHDs (44\%); $20 \%$ of patients used injectables other than insulin (Table 5). The majority of discontinuers (52\%) stated they had higher blood glucose levels than before discontinuation, while $28 \%$ stated that they were the same and $18 \%$ stated that they were lower than before discontinuation.The likelihood of restarting insulin was slightly/not at all likely for $42 \%$, somewhat for $40 \%$ and very likely for $18 \%$ of discontinuers.

\section{Discussion}

The experiences and feelings before, during, and after basal insulin initiation in patients who continue, interrupt and restart, or discontinue insulin treatment in Spain are largely unknown. The presented data from a subset of 150 Spanish participants of a multinational online survey of a total of 942 individuals provide insights into the experience of insulin initiation from a patient's perspective and factors contributing to different treatment persistence behaviours $[13,16]$.

Global and Spanish participants of the online survey were 
Table 5. Additional features of patients who interrupted/discontinued basal insulin in the global and Spanish samples.

\begin{tabular}{|c|c|c|c|c|}
\hline \multirow[t]{2}{*}{ Variable } & \multicolumn{2}{|c|}{ Interruption } & \multicolumn{2}{|c|}{ Discontinuation } \\
\hline & $\begin{array}{l}\text { Global }^{1}(\mathrm{~N}=942) \\
\text { Interrupters: } \\
\mathrm{n}=330\end{array}$ & $\begin{array}{l}\text { Spain }^{2}(\mathrm{~N}=150) \\
\text { Interrupters: } \\
\mathrm{n}=50\end{array}$ & $\begin{array}{l}\text { Global }^{1} \\
(\mathrm{~N}=942) \\
\text { Discontinuers: } \\
\mathbf{n}=255\end{array}$ & $\begin{array}{l}\text { Spain }^{2}(\mathrm{~N}=150) \\
\text { Discontinuers: } \\
\mathrm{n}=50\end{array}$ \\
\hline More than one interruption ${ }^{\star} \%$ & $62 \%$ & $66 \%$ & N/A & N/A \\
\hline $\begin{array}{l}\text { Duration of interruption } \\
1 \text { week } \\
>1 \text { week but }<1 \text { month } \\
\geq 1 \text { month but }<2 \text { months } \\
2 \text { to } 3 \text { months } \\
4 \text { to } 6 \text { months } \\
7 \text { to } 12 \text { months } \\
>12 \text { months }\end{array}$ & $\begin{array}{l}50 \% \\
24 \% \\
12 \% \\
9 \% \\
3 \% \\
2 \% \\
0 \% \\
\end{array}$ & $\begin{array}{l}66 \% \\
22 \% \\
8 \% \\
0 \% \\
0 \% \\
4 \% \\
0 \% \\
\end{array}$ & N/A & $\mathrm{N} / \mathrm{A}$ \\
\hline $\begin{array}{l}\text { Methods of managing blood glucose during interruption } \\
\text { discontinuation, \% }\end{array}$ & & & & \\
\hline $\begin{array}{l}\text { Exercise } \\
\text { Diet } \\
\text { Other antihyperglycaemic medications }\end{array}$ & $\begin{array}{l}63 \% \\
65 \%\end{array}$ & $\begin{array}{l}66 \% \\
78 \%\end{array}$ & $\begin{array}{l}66 \% \\
76 \%\end{array}$ & $\begin{array}{l}72 \% \\
82 \%\end{array}$ \\
\hline $\begin{array}{l}\text { Oral antihyperglycaemic drugs } \\
\text { Injectables other than insulin } \\
\text { Other types of insulin } \\
\text { Other } \\
\text { Nothing }\end{array}$ & $\begin{array}{l}46 \% \\
18 \% \\
9 \% \\
1 \% \\
4 \%\end{array}$ & $\begin{array}{l}58 \% \\
16 \% \\
8 \% \\
2 \% \\
0 \%\end{array}$ & $\begin{array}{l}43 \% \\
18 \% \\
7 \% \\
0 \% \\
2 \%\end{array}$ & $\begin{array}{l}44 \% \\
20 \% \\
6 \% \\
0 \% \\
2 \%\end{array}$ \\
\hline $\begin{array}{l}\text { Blood glucose levels during interruption/after discontinu } \\
\text { Higher than before interruption } \\
\text { Same as before interruption } \\
\text { Lower than before interruption } \\
\text { Not monitored }\end{array}$ & $\begin{array}{l}46 \% \\
39 \% \\
10 \% \\
6 \%\end{array}$ & $\begin{array}{l}46 \% \\
48 \% \\
6 \% \\
0 \%\end{array}$ & $\begin{array}{l}31 \% \\
48 \% \\
18 \% \\
3 \%\end{array}$ & $\begin{array}{l}52 \% \\
28 \% \\
18 \% \\
2 \%\end{array}$ \\
\hline $\begin{array}{l}\text { Likelihood of restarting basal insulin (discontinuers), \% } \\
\text { Very likely } \\
\text { Somewhat likely } \\
\text { Slightly/not at all likely }\end{array}$ & $\mathrm{N} / \mathrm{A}$ & $\mathrm{N} / \mathrm{A}$ & $\begin{array}{l}20 \% \\
40 \% \\
40 \%\end{array}$ & $\begin{array}{l}18 \% \\
40 \% \\
42 \%\end{array}$ \\
\hline
\end{tabular}

For participants who interrupted insulin therapy more than once, questions regarding interruption were asked specifically about the first time that they interrupted therapy.

${ }^{1}$ Overall results were weighted to give equal representation to each of the seven countries in our data. Due to rounding, some counts may not sum to equal one another and some percentages may not appear correct.

${ }^{2}$ Results specific to Spain were not weighted.

Abbreviations: N/A, not applicable.

younger when compared with the mean age of people with T2DM generally $[17,18]$, possibly because the survey was online, which might attract participants of younger age. Spanish as well as global continuers were on average older than interrupters and discontinuers. Other studies have shown an association between older age and increased likelihood of persistence after basal or premixed insulin initiation $[8-10,19,20]$. A study by Barrot-de la Puente et al. showed that, in Spain, glycaemia was under better control in patients $>65$ years [21]. Spanish and global continuers had lower rates of AHDs than interrupters and had similar rates to discontinuers [13]. This is in contrast to findings from previous studies concluding that prior use of multiple classes of AHDs was associated with a higher likelihood of persistence $[\mathbf{9 , 1 0 , 2 2 ]}$. This may possibly be due to the young age of interrupters in the current study, as in younger patients insulin is more likely a treatment option (connected to the lower use of prior AHDs) than a necessity (connected to a high use of prior AHDs).

Physicians/HCPs might play an important role in motivating Spanish patients to start insulin, since encouragement from physicians/HCPs was the most commonly stated reason to start insulin treatment. A significantly higher rate of continuers than discontinuers in Spain reported that their views were very much or fully considered in the decision to start insulin and significantly more discontinuers than continuers believed that insulin was not necessary. Concerns before and after initiation of insulin were similar to those reported in prior studies and were centred around the fear of self-injection, the risk of hypoglycaemia, weight gain and less flexibility in their lifestyle [23,24]. In the current study, just like the global participants, Spanish continuers were less likely to experience specific challenges following insulin initiation than discontinuers or interrupters. Continuers in the global population were also less likely to have concerns before and after initiating 
insulin. This pattern was similar in the Spanish population but not significant. All of the concerns at insulin initiation that were reported by significantly more discontinuers than continuers did not differ between these two groups after 1 week of insulin use, but the fear of self-injection and the concern that "he/she would need to monitor blood glucose more often" was significantly more common in discontinuers after 1 week. In the overall Spanish population, the percentage of participants having concerns either dropped or stayed the same for all 14 items. For some patients, it therefore seems as though concerns were baseless, while - for patients in the discontinuers group - some additional concerns appeared as a result of their experiences during and after the first week of insulin use.

In this study, continuers were less likely than discontinuers to report uncontrolled high blood glucose and less likely than interrupters to report symptoms of hypoglycaemia. The absence of adverse events and seeing the benefits of therapy most likely motivates patients to continue with insulin. However, any comparisons between the persistence groups were subject to the limitations mentioned below, eg, the exposure to insulin was not captured in the survey.

For $68 \%$ of the continuers, there was more than one reason to continue: improved glycaemic control was the most common reason (70\%), very similar to the percentage of the global population (71\% [Data on file, Eli Lilly and Company]). This could mean that continuers are convinced by the therapy itself and are not just doing what their doctor told them (instruction by physician/HCP to continue: $32 \%$ ).

The most common reason to interrupt insulin therapy was weight gain (46\%); however, when looking at these patients, only $65 \%$ of them reported actually experiencing weight gain. For the remaining $35 \%$ who did not actually gain weight, we interpret the reason to interrupt as the fear or anticipation of weight gain. Similarly, only $55 \%$ of patients interrupting because of hypoglycaemia ( $40 \%$ of interrupters) actually experienced hypoglycaemia, while the remaining patients $(45 \%)$ were only worried about hypoglycaemia. Patient attitudes contributing to resistance to insulin therapy have been explored in several studies and, indeed, patients believe that taking insulin leads to poor outcomes, including weight gain and hypoglycaemia [14]. Better training and education may help patients to have more realistic expectations of insulin use and educate them on how to react in adverse event situations. Also, better training can encourage patients to continue insulin treatment when these events occur. The interrupters seem to be a heterogeneous group of patients, with some patients not following the instructions from their $\mathrm{HCP}$, and some may feel that they have their disease under control and are confident about their disease management. Only 20\% of interrupters restarted due to insufficient glycaemic control without insulin, while $72 \%$ started because of persuasion by physician/ $\mathrm{HCP}$. This could mean that they are not as convinced as the continuers about this therapy.
Similar to interrupters, $40 \%$ of discontinuers stated weight gain as a reason for discontinuation, and $65 \%$ of them actually experienced weight gain. Additional most common reasons to discontinue were pain from injections and dislike/fear of needles. Providing better training and education could lessen injection pain and reduce the fear of needles. Only $20 \%$ of discontinuers reported that they stopped because of hypoglycaemia. Interestingly, only $30 \%$ of these participants actually reported experiencing hypoglycaemia, leading to the conclusion that $70 \%$ permanently stopped treatment because of fear of hypoglycaemia. By far the most common potential reason to restart insulin was persuasion by the physician/ HCP to restart (78\%). This could mean that discontinuers are less convinced of the benefits of insulin therapy compared with continuers.

Nonetheless, the relatively high number of concerns before and after insulin initiation and challenges during the first week of insulin use across the persistence groups indicates that there is a clear opportunity to improve patients' expectations and experiences during insulin initiation across all persistence groups.

Although providing interesting new insights, this study is subject to several limitations.

First, all data evaluated in this study were provided by patients, and no clinical data on outcomes such as weight, rate of hypoglycaemia, $\mathrm{HbA} 1 \mathrm{c}$ levels and others were captured. Additionally, as patients were evaluated for a minimum of 3-6 months and the persistence category was self-reported, there is the possibility of misclassification, eg, discontinuers may restart or continuers may stop later. In this survey, clinical information about diagnosis or severity of illness was not captured; therefore, the relationship between clinical measures and basal insulin persistence remains unknown.

Second, the sample might not be generalisable to all patients with T2DM in Spain for several reasons: As it was an online survey, the participants were of younger age, which is also connected to working status and education, and the rate of prior AHD use was lower and the rate of prior non-insulin injectable treatment higher than expected. Participants were identified from groups of individuals who had agreed to be contacted for studies. Other limitations typical for using a web-based data collection method may apply [25].

Third, the descriptive design of the study does not adjust for plausible confounders like demographics and disease and treatment characteristics.

Fourth, as with all data based on surveys, recall bias, selection bias, and social desirability bias (survey responses were confidential, and participants were permitted to select multiple reasons to minimise this effect) might have influenced the results.

Finally, there might have been other factors influencing treatment that were not robustly captured in this study, eg, we have no data on how often the participants injected and/or at what time of the day, which could also influence the persistence patterns. 
It is a particular strength of our study that the evaluated factors in the online survey had previously been systematically identified by qualitative interviews in the respective countries.

The findings from this study can be used for further studies, monitoring for possible confounding variables for insulin persistence.

\section{Conclusion}

This study describes the real-world experiences of people with T2DM in Spain who have different patterns of persistence after initiating basal insulin. Our data suggest that continuers understand the benefits of using basal insulin. While interrupters most commonly state side effects and the inconvenience of using insulin as a reason for interruption, discontinuers report injection-related factors (pain, dislike/fear of needles) as reasons to stop.

Our data support the need to address patient concerns and set realistic expectations when initiating insulin. Understanding and addressing patients' feelings and concerns before and during initiation will help physicians manage T2DM care with basal insulin analogues more effectively and will help patients achieve their glycaemic target. Future research in a more representative sample is required to understand what detailed actions are needed from physicians/HCPs to motivate patients to start and continue taking basal insulin.

\section{Competing interests}

Miriam Rubio, Tatiana Dilla, Irene Hadjiyianni, Magaly Perez-Nieves, and Dachuang Cao are employees of Eli Lilly and Company and own Eli Lilly stock. Jasmina Ivanova is an employee of Analysis group, Inc., which received research funding for this study from Eli Lilly and Company. Juan José Gorgojo Martínez did not receive any research funding for this work but has previously had the following financial relationships: advisor on scientific boards for AstraZeneca, Janssen Pharmaceuticals, Eli Lilly and Company, Merck Sharp \& Dohme and Novo Nordisk; lecturer for Abbott, AbbVie Inc, AstraZeneca, Boehringer Ingelheim Pharmaceuticals, Inc., Esteve, Janssen Pharmaceuticals, Eli Lilly and Company, Merck Sharp \& Dohme, Novo Nordisk, Roche Pharma and Sanofi-Aventis; and research activities for AstraZeneca and Sanofi-Aventis.

\section{Authors' contributions}

\begin{tabular}{|l|c|c|c|c|c|c|c|}
\hline Authors' contributions & MRS & IH & MP & DC & JI & TD & JJGM \\
\hline Research concept and design & -- & $\checkmark$ & $\checkmark$ & $\checkmark$ & $\checkmark$ & -- & -- \\
\hline Collection and/or assembly of data & -- & -- & -- & -- & $\checkmark$ & -- & -- \\
\hline Data analysis and interpretation & $\checkmark$ & $\checkmark$ & $\checkmark$ & $\checkmark$ & $\checkmark$ & $\checkmark$ & $\checkmark$ \\
\hline Writing the article & $\checkmark$ & $\checkmark$ & $\checkmark$ & $\checkmark$ & $\checkmark$ & $\checkmark$ & $\checkmark$ \\
\hline Critical revision of the article & $\checkmark$ & $\checkmark$ & $\checkmark$ & $\checkmark$ & $\checkmark$ & $\checkmark$ & $\checkmark$ \\
\hline Final approval of article & $\checkmark$ & $\checkmark$ & $\checkmark$ & $\checkmark$ & $\checkmark$ & $\checkmark$ & $\checkmark$ \\
\hline Statistical analysis & -- & -- & -- & -- & $\checkmark$ & -- & -- \\
\hline
\end{tabular}

\section{Acknowledgements and Funding}

Medical writing assistance was provided by Doris Hummel, PhD, Eli Lilly and Company.

This study was funded by Eli Lilly and Company.

Publication history

Editor: Geoffrey Burnstock, University College London, UK.

Received: 15-Mar-2019 Final Revised: 25-April-2019

Accepted: 30-April-2019 Published: 14-May-2019

\section{References}

1. Soriguer F, Goday A, Bosch-Comas A, Bordiu E, Calle-Pascual A, Carmena R, Casamitjana R, Castano L, Castell C, Catala M, Delgado E, Franch J, Gaztambide S, Girbes J, Gomis R, Gutierrez G, Lopez-Alba A, MartinezLarrad MT, Menendez E, Mora-Peces I, Ortega E, Pascual-Manich G, Rojo-Martinez G, Serrano-Rios M, Valdes S, Vazquez JA and Vendrell J. Prevalence of diabetes mellitus and impaired glucose regulation in Spain: the Di@bet.es Study. Diabetologia. 2012; 55:88-93. | Article | PubMed Abstract | PubMed FullText

2. Crespo C, Brosa M, Soria-Juan A, Lopez-Alba A, López-Martínez N and Soriae B. Direct cost of diabetes mellitus and its complications in Spain (SECCAID Study: Spain Estimated Cost Ciberdem-Cabimer in Diabetes). Avances Diabetologia. 2013 ; 29:182-89. | Article
3. Gomez-Peralta F, Escalada San Martin FJ, Menendez Torre E, Mata Cases M, Ferrer Garcia JC, Ezkurra Loiola P, Avila Lachica L, Fornos Perez JA, Artola Menendez S, Alvarez-Guisasola F, Rica Echevarria I and Girbes Borras J. Spanish Diabetes Society (SED) recommendations for the pharmacologic treatment of hyperglycemia in type $\mathbf{2}$ diabetes: 2018 Update. Endocrinol Diabetes Nutr. 2018; 65:611-624 . | Article I PubMed

4. Minambres I, Mediavilla JJ, Sarroca J and Perez A. Meeting individualized glycemic targets in primary care patients with type $\mathbf{2}$ diabetes in Spain. BMC Endocr Disord. 2016; 16:10. | Article | PubMed Abstract | PubMed FullText

5. Lind $M$, Oden $A$, Fahlen $M$ and Eliasson $B$. The true value of HbA1c as a predictor of diabetic complications: simulations of HbA1c variables. 
PLoS One. 2009; 4:e4412. | Article | PubMed Abstract | PubMed FullText

6. Holman RR, Paul SK, Bethel MA, Matthews DR and Neil HA. 10-year follow-up of intensive glucose control in type 2 diabetes. $N$ Engl $\mathrm{J}$ Med. 2008; 359:1577-89. | Article | PubMed

7. Inzucchi SE, Bergenstal RM, Buse JB, Diamant M, Ferrannini E, Nauck M, Peters AL, Tsapas A, Wender R and Matthews DR. Management of hyperglycaemia in type 2 diabetes, 2015: a patient-centred approach. Update to a position statement of the American Diabetes Association and the European Association for the Study of Diabetes. Diabetologia. 2015; 58:429-42. | Article | PubMed

8. Wei W, Pan C, Xie L and Baser O. Real-world insulin treatment persistence among patients with type 2 diabetes. Endocr Pract. 2014; 20:52-61. | Article | PubMed

9. Ascher-Svanum H, Lage MJ, Perez-Nieves M, Reaney MD, Lorraine J, Rodriguez $A$ and Treglia M. Early discontinuation and restart of insulin in the treatment of type 2 diabetes mellitus. Diabetes Ther. 2014; 5:22542. | Article | PubMed Abstract | PubMed FullText

10. Perez-Nieves M, Kabul S, Desai U, Ivanova JI, Kirson NY, Cummings AK, Birnbaum HG, Duan R, Cao D and Hadjiyianni I. Basal insulin persistence, associated factors, and outcomes after treatment initiation among people with type 2 diabetes mellitus in the US. Curr Med Res Opin. 2016; 32:669-80. | Article | PubMed

11. Hadjiyianni I, Desai U, Ivanova JI, Kirson NY, Enloe CJ, Cummings AG, Birnbaum HG, Suzuki SJ, Duan R, Raibouaa A, Cao D and Perez-Nieves $\mathrm{M}$. Basal insulin persistence, associated factors, and outcomes after treatment initiation among people with type 2 diabetes mellitus in Japan. Value Health. 2015; 18:A611-2. | Article I PubMed

12. Spain CV, Wright JJ, Hahn RM, Wivel A and Martin AA. Self-reported barriers to adherence and persistence to treatment with injectable medications for type 2 diabetes. Clin Ther. 2016; 38:1653-1664 e1. | Article | PubMed

13. Perez-Nieves M, Ivanova JI, Hadjiyianni I, Zhao C, Cao D, Schmerold L, Kalirai S, King S, DeLozier AM, Birnbaum HG and Peyrot M. Basal insulin initiation use and experience among people with type 2 diabetes mellitus with different patterns of persistence: results from a multinational survey. Curr Med Res Opin. 2017; 33:1833-1842. | Article | PubMed

14. Peyrot M, Rubin RR, Lauritzen T, Skovlund SE, Snoek FJ, Matthews DR, Landgraf $R$ and Kleinebreil $L$. Resistance to insulin therapy among patients and providers: results of the cross-national Diabetes Attitudes, Wishes, and Needs (DAWN) study. Diabetes Care. 2005; 28:2673-9. I Article | PubMed

15. Polinski JM, Kim SC, Jiang D, Hassoun A, Shrank WH, Cos X, RodriguezVigil E, Suzuki S, Matsuba I, Seeger JD, Eddings W, Brill G and Curtis BH. Geographic patterns in patient demographics and insulin use in 18 countries, a global perspective from the multinational observational study assessing insulin use: understanding the challenges associated with progression of therapy (MOSAIc). BMC Endocr Disord. 2015; 15:46. | Article | PubMed Abstract | PubMed FullText

16. Peyrot M, Perez-Nieves M, Ivanova J, Cao D, Schmerold L, Kalirai S and Hadjiyianni I. Correlates of basal insulin persistence among insulin-naive people with type 2 diabetes: results from a multinational survey. Curr Med Res Opin. 2017; 33:1843-1851. | Article | PubMed

17. National Center for Chronic Disease Prevention and Health Promotion, Division of Diabetes Translation. National diabetes statistics report, 2017: Estimates of diabetes and its burden in the United States. 2017. I Pdf

18. Alonso-Moran E, Orueta JF, Esteban JI, Arteagoitia Axpe JM, Marqués González ML, Polanco NT, Loiola PE, Gaztambide S and Nuño-Solinis R. Prevalence and quality of care indicators of type 2 diabetes in the population of the Basque Country (Spain). Avances Diabetologia. 2015; 31:72-9. | Article

19. Yavuz DG, Ozcan S and Deyneli O. Adherence to insulin treatment in insulin-naive type 2 diabetic patients initiated on different insulin regimens. Patient Prefer Adherence. 2015; 9:1225-31. | Article | PubMed Abstract | PubMed FullText

20. Cooke CE, Lee HY, Tong YP and Haines ST. Persistence with injectable antidiabetic agents in members with type 2 diabetes in a commercial managed care organization. Curr Med Res Opin. 2010; 26:231-8. | Article I PubMed

21. Barrot-de la Puente J, Mata-Cases M, Franch-Nadal J, Mundet-Tuduri X, Casellas A, Fernandez-Real JM and Mauricio D. Older type 2 diabetic patients are more likely to achieve glycaemic and cardiovascular risk factors targets than younger patients: analysis of a primary care database. Int J Clin Pract. 2015; 69:1486-95. | Article | PubMed Abstract I PubMed FullText

22. Levin PA, Zhou S, Gill J and Wei W. Health outcomes associated with initiation of basal insulin after 1,2 , or $>/=3$ oral antidiabetes drug(s) among managed care patients with type 2 diabetes. J Manag Care Spec Pharm. 2015; 21:1172-81. | Article | PubMed

23. Larkin ME, Capasso VA, Chen CL, Mahoney EK, Hazard B, Cagliero E and Nathan DM. Measuring psychological insulin resistance: barriers to insulin use. Diabetes Educ. 2008; 34:511-7. | Article | PubMed

24. Polonsky WH, Fisher L, Guzman S, Villa-Caballero L and Edelman SV. Psychological insulin resistance in patients with type 2 diabetes: the scope of the problem. Diabetes Care. 2005; 28:2543-5. | Article | PubMed

25. Hays RD, Liu $\mathrm{H}$ and Kapteyn A. Use of Internet panels to conduct surveys. Behav Res Methods. 2015; 47:685-90. | Article | PubMed Abstract | PubMed FullText

\section{Citation:}

Rubio de Santos M, Hadjiyianni I, Perez-Nieves M, Cao D, Ivanova J, Dilla T and Gorgojo-Martinez JJ. Treatment persistence behaviours in patients with type 2 diabetes (T2DM) after initiation of basal insulin: An exploratory analysis from a Spanish real-world sample. J Diab Res Clin Met. 2019; 8:1. http://dx.doi.org/10.7243/2050-0866-8-1 